\title{
Energy saving and environmental benefits of metal box vegetal facades
}

\author{
F. Olivieri, F. J. Neila \& C. Bedoya \\ Department of Construction Technology and Architecture, \\ Technical University of Madrid, Spain
}

\begin{abstract}
The aim of this research work is evaluating energy saving and environmental benefits of vegetal façades in comparison to traditional façades. In order to achieve this objective, a particular type of vegetal façade has been studied and installed in an experimental building. A similar façade without the vegetation layer has also been installed in the same building in order to compare both façade models. All the components of the two experimental façades are monitored by state probes that register temperature data of the layers that conform each experimental closing module in periods of five minutes. In addition, a weather station that has been installed in the same experimental building provides data about solar radiation, humidity, pluviometry, wind speed. Results show that during summer time the temperature of those layers of the façade with vegetation are lower than the one registered in the facade without vegetation. The reason of this fact is that the temperature of the leaves is similar to the one of the air, whereas the outside cladding is overheated due to the action of solar radiation. In the case of winter, the vegetation layer goes on with its role of a solar protection element and this means negative effects for the optimal use of solar radiation in walling. In conclusion, the optimal use of these prototypes of façades according to the climate of Colmenar Viejo (Madrid), whose climatic characteristics are hot summers and cold winters, carries important benefits related to comfort conditions in buildings. The way to optimize the system in winter consists on the incorporation of deciduous vegetation in the façades prototypes.
\end{abstract}

Keywords: vegetal façade, experimental building, energy saving, evaporative cooling effect, thermal comfort, adiabatic space, monitoring method, state sensor. 


\section{Introduction}

In the last years, energy and environmental problems have become more serious in Spain. Energy use is the main contributor to atmospheric $\mathrm{CO}_{2}$. In such a situation to increase urban vegetation is more and more necessary. The research $[1,3]$ and development of roof gardens and vegetal façades have been increasing, since these strategies are effective not only in positive climate effects but also in energy conservation. Strategies that increase urban vegetation not only assure a lower level of $\mathrm{CO}_{2}$ [2] emissions, but also provide a cost saving to individual homeowners and consumers and reduce energy consumption citywide. These strategies also serve to reduce smog, something very important in those cities where the air pollution is a significant problem. In addition to their aesthetic value, vegetal façades can modify the microclimate of the zone, improving urban thermal comfort in hot climate [4]. In hot climates, such as Spanish summers, the evaporative cooling effect [5] of vegetal façades is effective in reducing the heat that penetrates the building.

\section{Outline of the research}

The present research project is being developed by the Department of Construction and Technology in Architecture (DCTA) from the Technical University of Madrid (UPM). The investigation started two years ago with the collaboration of the private company Intemper Española, S.A. [6].

The aim of the project is to analyze the characteristics and benefits of the incorporation of vegetal elements in façades in relation with the internal space. Final results will determine percentages of energy savings as well as potential environmental benefits of vegetal façades through the comparison between this prototype and a conventional façade.

The project started at the end of 2007 with the installation of four façades in an experimental building in Colmenar Viejo (Madrid). The initial site works started in November 2008. The constructive systems used include two translucent solutions and two opaque solutions.

\section{Monitored experimental building}

The present paper describes the analysis of opaque façades. What makes the two cases different is the vegetal layer incorporated in one of them.

The system consists of modular vegetal panels with the following components: evergreen vegetation, metal box $(60 \times 60 \times 8 \mathrm{~cm})$, synthetic structure, substrate, drip irrigation system, coupling structure and vertical structure.

A room size of $180 \times 180 \times 240 \mathrm{~cm}$ for each façade is considered in order to monitor the constructive strategy. It consists of adiabatic space (polystyrene layer $60 \mathrm{~cm}$ thick) where state probes are placed in order to ensure the accuracy of the experimental data registered. 


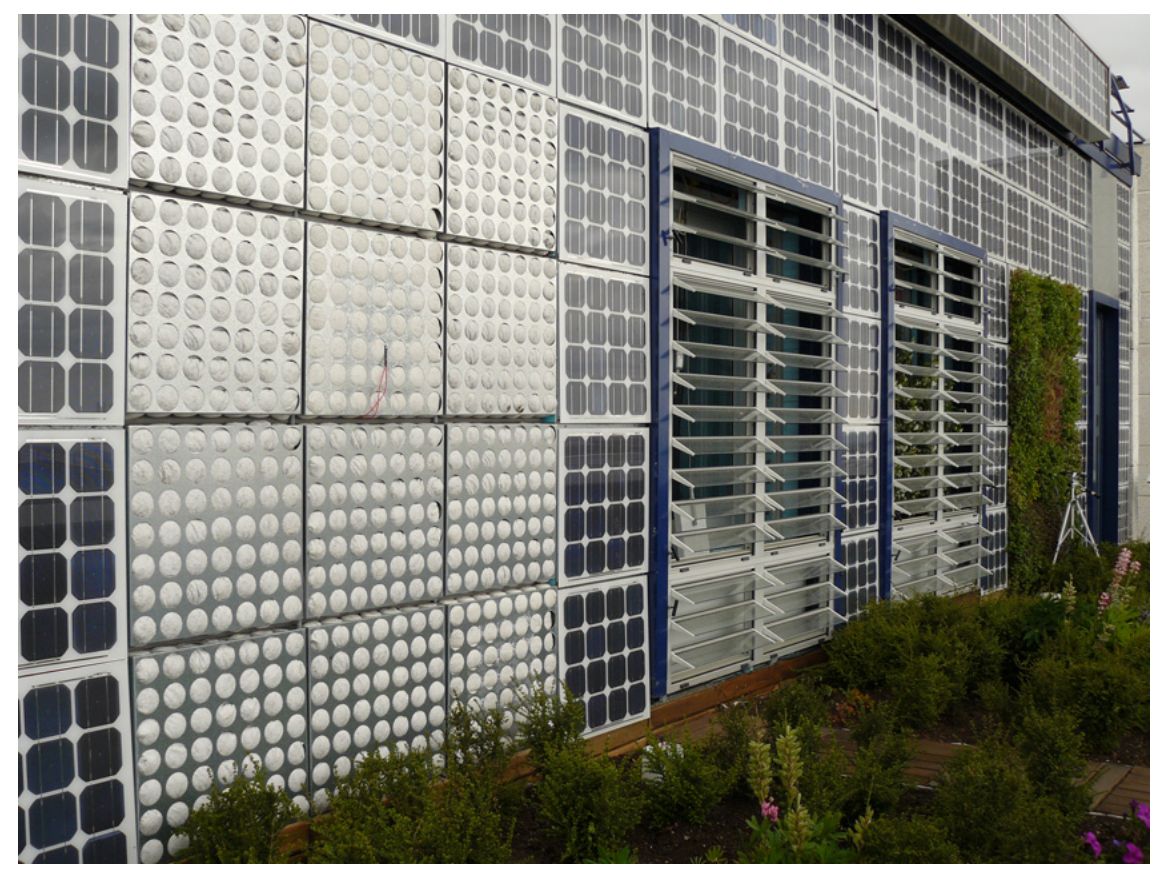

Figure 1: Experimental building.

\section{Site measurements}

\subsection{Experimental procedures}

Registered data from the vegetal façade are being compared with values measured in the façade without vegetation. In order to preserve the right growth of vegetation in the green façade, a modular design has been applied to achieve an easy replacement of the vegetal element in those modules where vegetation could have dried out.

The accuracy of the presented experimental prototype is verified on the basis of a comprehensive set of experimental data.

The monitoring method achieves the registration of temperature data by state probes in each layer of the envelope of the modules, from outdoors to indoors. Two surface probes have been installed: one behind the panel and another between the sheet metal layer and the felt element. In addition, the vegetal panel has an ambient temperature probe placed among the leaves.

Other ambient temperature probes are located indoors and outdoors the adiabatic rooms as follows: in the middle, close to the floor and close to the ceiling. A cable protector's tube has been also incorporated and hence, future installations of probes could be included. This tube is sealed with polyurethane foam in order to prevent temperature and air transmissions. 


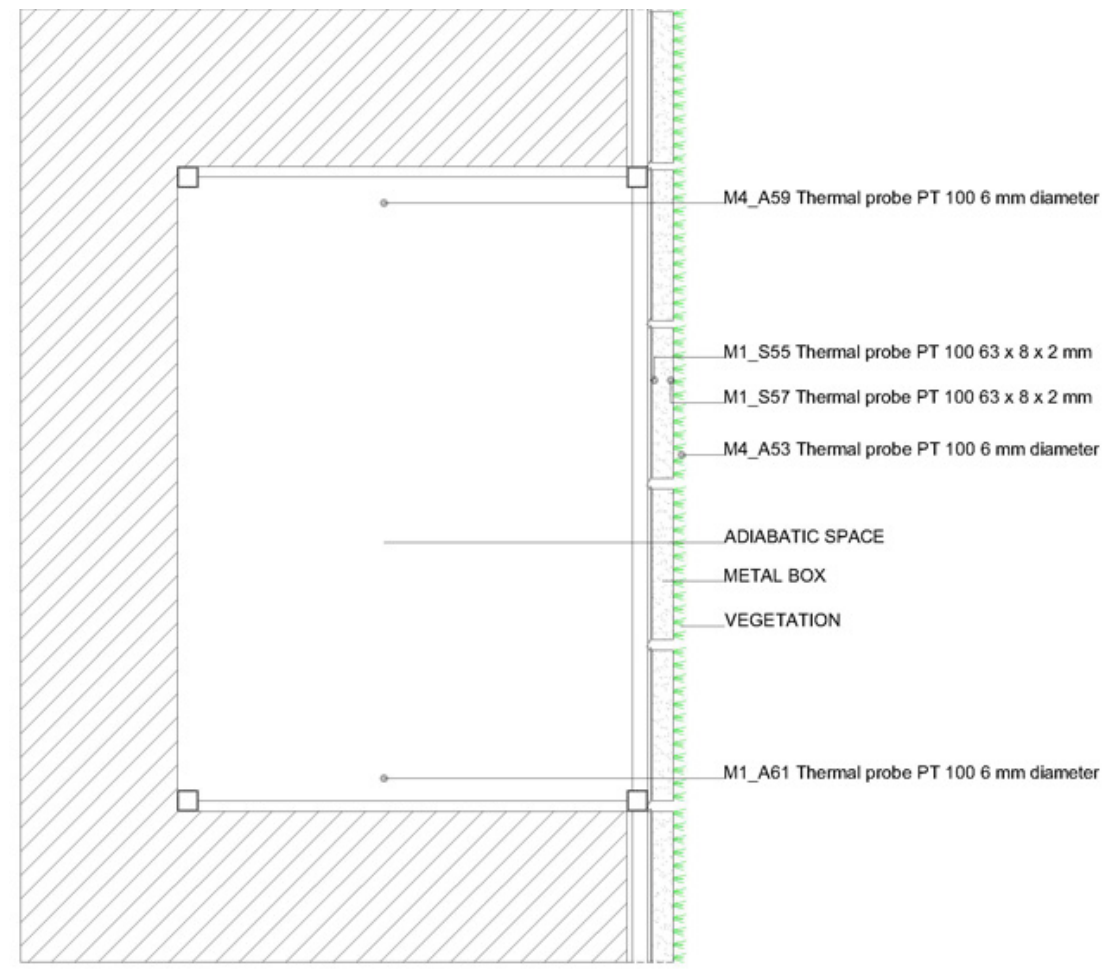

Figure 2: Vegetal façade. Adiabatic space and state probes.

\subsection{Measuring instruments: probes, weather station, software}

Surface temperature data from each component of the façade is registered by state probes (PT-100 flat $63 \times 8 \times 2 \mathrm{~mm}$ in three threads).

Other state probes, PT-100 (Thermal Resistant L=100 $\mathrm{mm}$ of $6 \mathrm{~mm}$ of diameter AISI-316 in 4 threads) are used to measure the ambient temperature in each localization. The outdoors probes that could be affected by direct solar radiation are protected by placement inside a box specially designed.

In order to test the accuracy of the measures in all the cases, the installation of probes has been duplicated. This duplicity is also useful in case of disqualification of measuring instruments or any other damage in the system. Hence, it would not be necessary any reinstallation.

A weather station incorporated to the roof of the experimental building registers data related to solar radiation, pluviometry, wind speed and outdoors relative humidity.

Each probe registers data in periods of five minutes. An average is obtained from each three values (15 minutes). This data is noticed in a spreadsheet that 


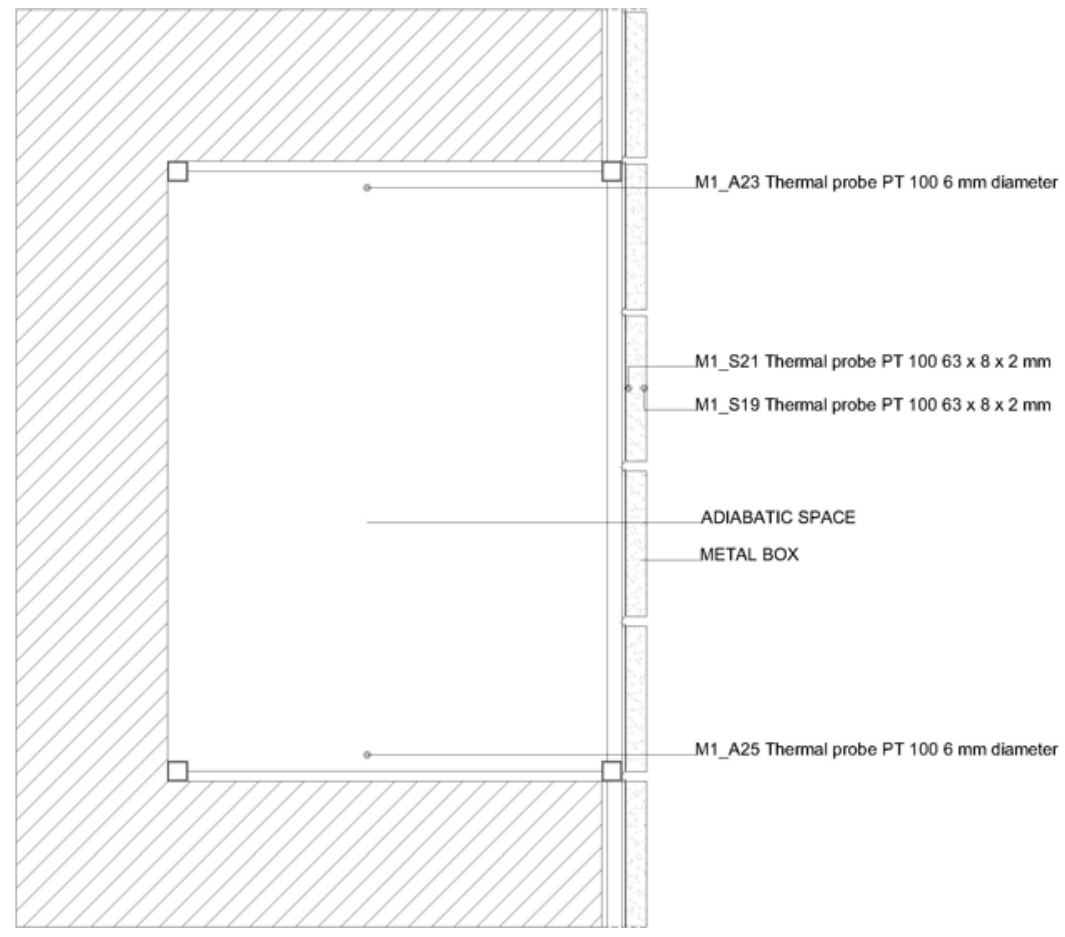

Figure 3: $\quad$ Façade without vegetation. Adiabatic space and state probes.

incorporates details about precise data and time. The resulting graph includes the probes that are expected to be represented in each moment, as well as the choice of the period of time. Scada data program registers this information and it has been installed in a conventional PC.

Besides, programmable automation equipment (M-340 Schneider) transforms the analog signals from probes and flow meters into temperature and flow values.

\subsection{Manual data handling}

The incorporation of state probe that could measure leaf surface temperature of plants has not been possible. This fact and the objective of comparing the leaf surface temperature with the air temperature behind the plants have been important in the decision of using surface probes connected by a thermometer Testo 400 in order to obtain punctual measurements.

Testo 400 is a precision thermometer that makes possible the connection of two probes at the same time. Nowadays, specific probes that can measure vegetal surface temperature do not exist. Hence, existing probes that were available in the market were used for this aim, although these are instruments particularly conceived to do measurements in another kind of surfaces. Two probes with 


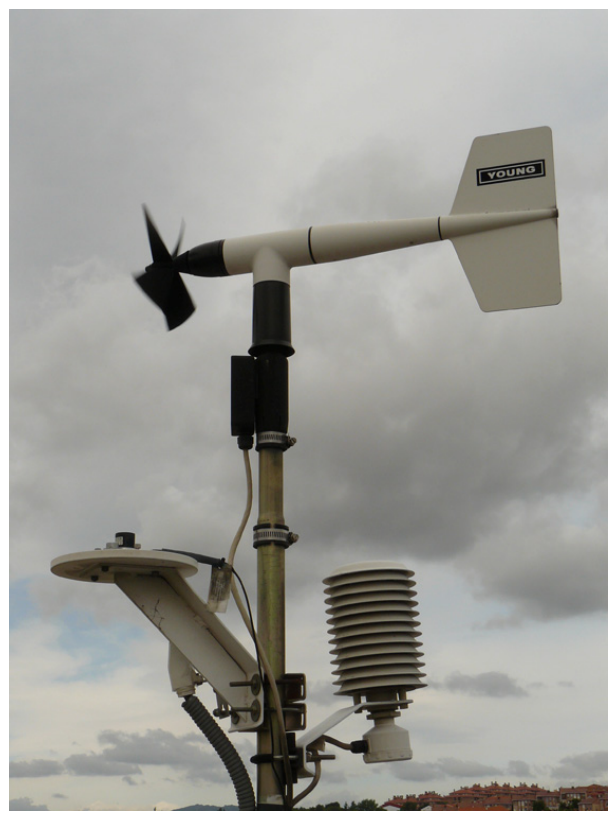

Figure 4: Weather station.

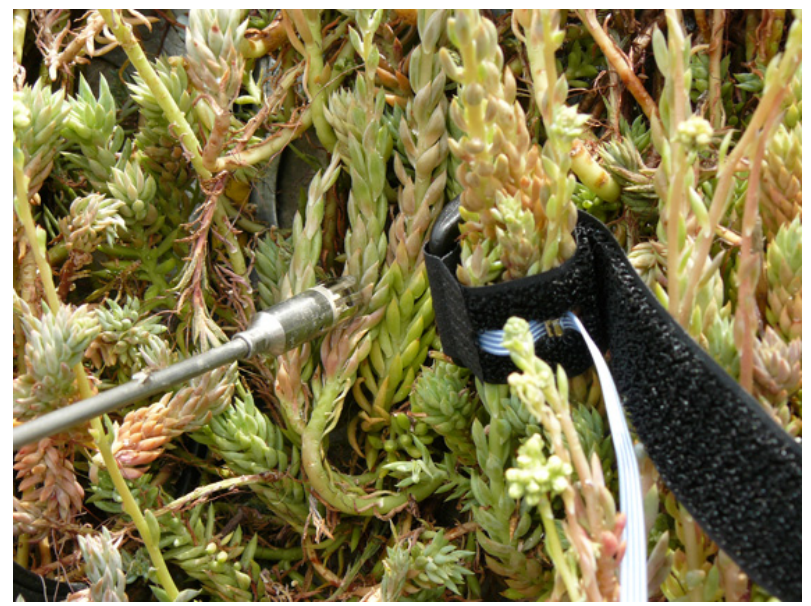

Figure 5: Manual data handling. Probes in contact whit the leaves surface.

different characteristics have been chosen. The first one is a high-speed probe of $\mathrm{NiCr}-\mathrm{Ni}$ type with band thermocouple and a measuring range between $-200^{\circ} \mathrm{C}$ and $+300^{\circ} \mathrm{C}$. Due to the shape of the leaves, the second probe incorporates Velcro for pipes with a $75 \mathrm{~mm}$ maximum diameter and a measuring range between $-50^{\circ} \mathrm{C}$ and $+150^{\circ} \mathrm{C}$. 
The data handling procedure with Testo 400 consisted of the placement of probes in contact with the leaves surface during those diurnal hours when the higher level of solar radiation is noticed. The procedure has been repeated during several days.

In addition, a thermographic camera is used to register specific measurements. However these data have been considered as supplementary information due to the uncertainty related with the emissivity value of vegetation. Several tests were made with the resultant emissivity values round 0.90 .

\section{Results and discussion}

\subsection{Spring period}

During diurnal hours, indoors temperature of the vegetal module is $20 \%$ lower than temperature data registered by sensors in the module without vegetation.

Thermal spikes inside vegetal modules are registered with a lag between three and four hours regarding the solar radiation spike.

Thermal fluctuation, the difference between registered minimum and maximum values inside the vegetal module, is lower than the one registered in the other module.

Through the comparison of data from surface probes located in both external and internal layers of the metal box, the important effect carried out due to the vegetation and the substrate has been noticeable. During days with higher solar radiation, a difference of $15^{\circ} \mathrm{C}$ could be reached.

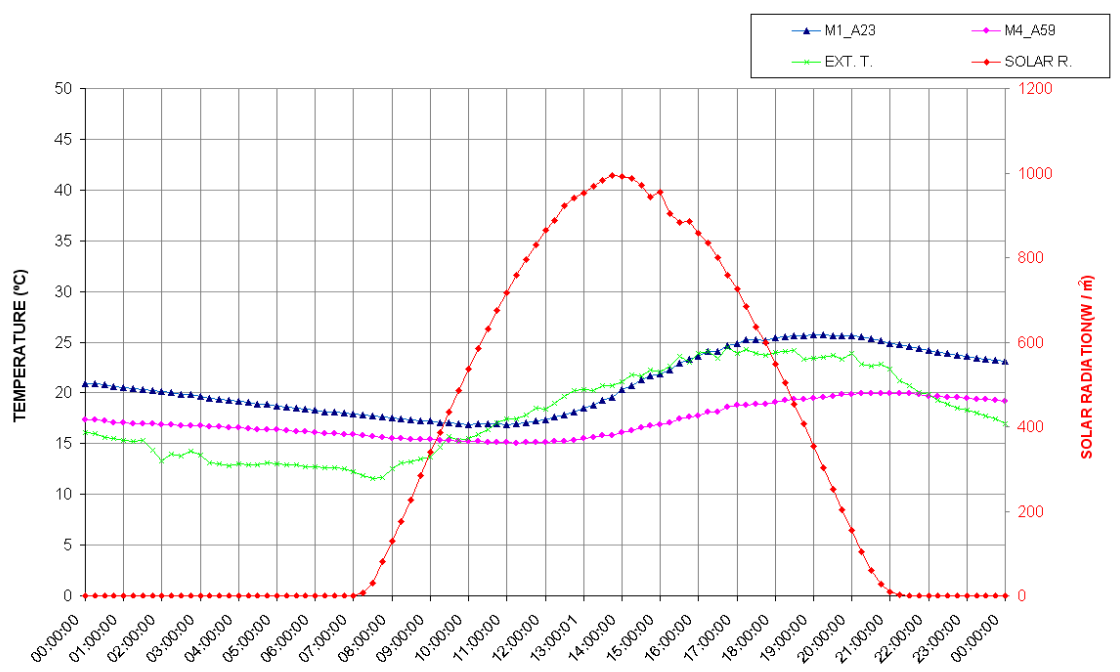

Figure 6: Example of a spring day. Data registered from the temperature probes located inside the both modules. 


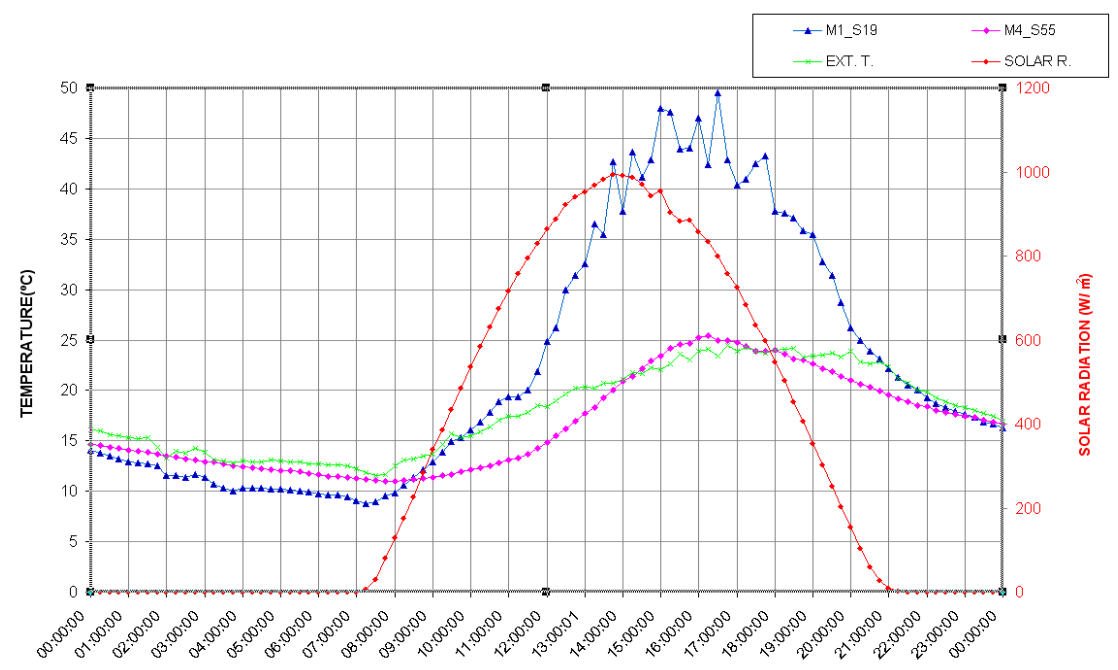

Figure 7: Example of a spring day. Data registered from the temperature probes located in externals layers of metal boxes.

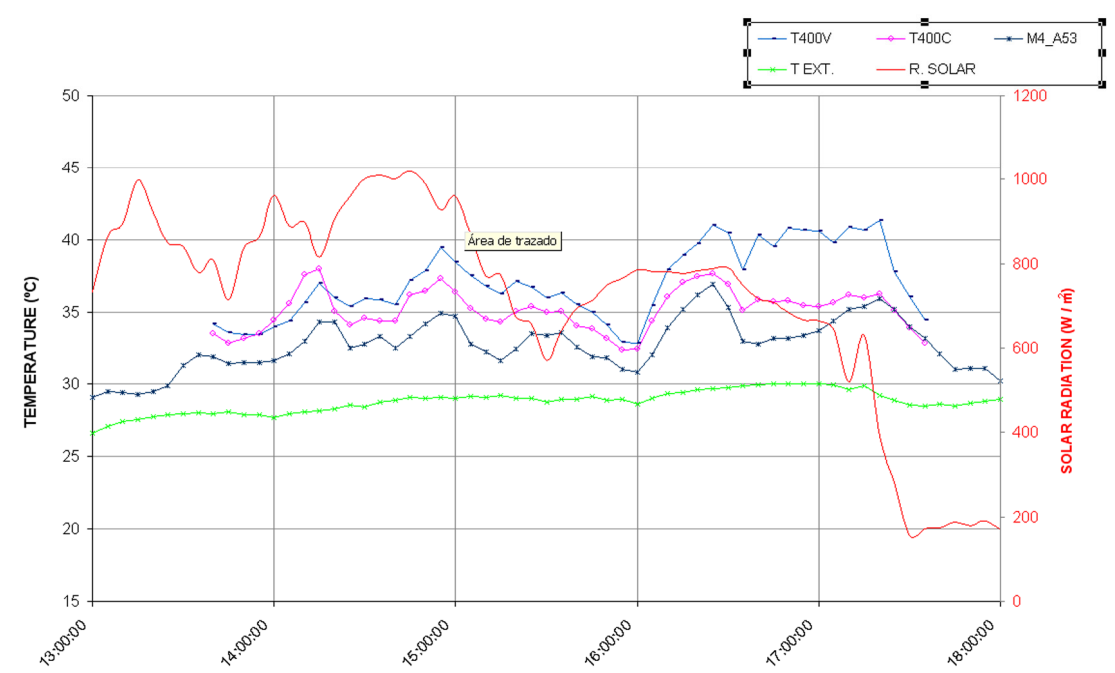

Figure 8: $\quad$ Example of a spring day. Data registered from the surface probes located directly in the leaves (T400V and T400C) and data registered from ambient temperature sensor (M4_A53) located behind them. 
Data from surface probes located directly in the vegetal surfaces demonstrated that the temperature of the leaves is higher than ambient temperature behind them (a difference between $2-4^{\circ} \mathrm{C}$ ). The reason of this fact could be related to the kind of vegetal species applied ('sedum') which retains a great percentage of water with lower evapotranspiration.

The two surface probes registered similar values. The probe with Velcro takes time in the registration of thermal fast changes due to its higher inertia. Another factor that involves a thermal difference between probes is the presence of wind. When the wind speed is increased, the surface probe $\mathrm{NiCr}-\mathrm{Ni}$ is affected. Then the measured temperature decreases quickly, while the other probe does not perceive that thermal variation as it incorporates a Velcro protection.

\subsection{Winter period}

Throughout those days with a great intensity of radiation, it is noticed a significant difference among temperature values in the envelope layers, especially indoor temperature of the adiabatic rooms. During the day, the façade without vegetation becomes heated due to the action of solar radiation. Outdoor layers could reach a difference of $15^{\circ} \mathrm{C}$ with the sensors from façades without vegetation. However, the thermal difference inside the adiabatic rooms does not exceed $3^{\circ} \mathrm{C}$. Throughout the night, this interval is reduced into $2^{\circ} \mathrm{C}$.

During days with low radiation, there are not important thermal variations. The thermal interval among sensors inside the adiabatic rooms is nearly $1^{\circ} \mathrm{C}$, and it is more or less a constant between day and night.

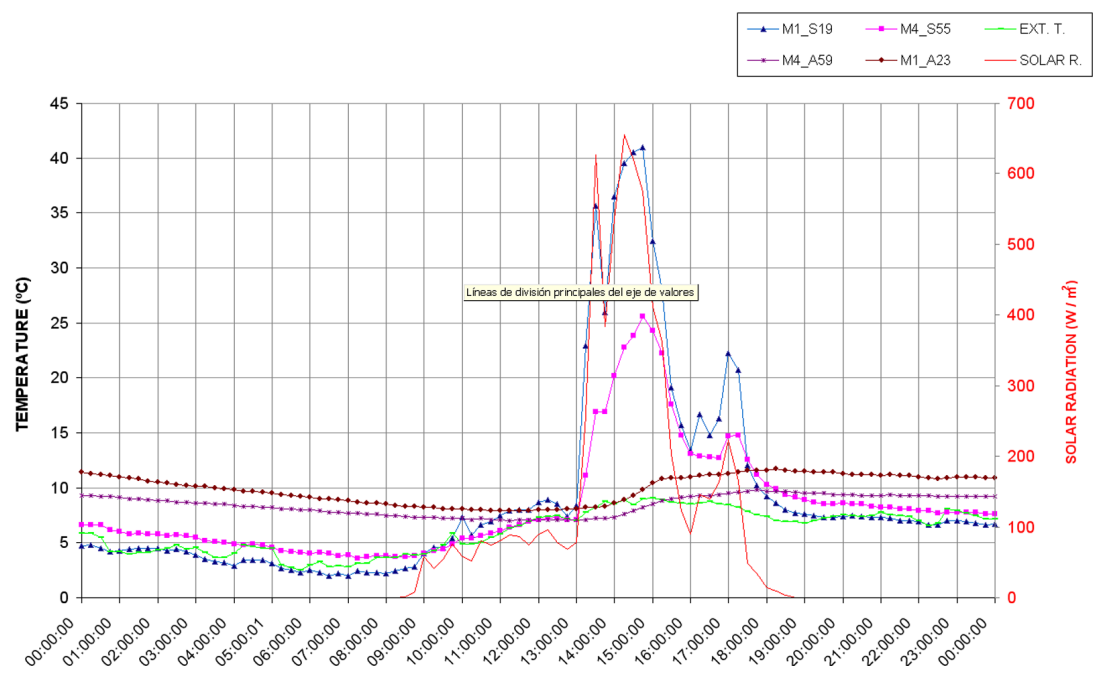

Figure 9: Example of a winter day. Data registered from the temperature probes located in externals layers of metal boxes and from the ambient temperature probes. 


\section{Conclusion}

Although current conclusions are not definitive as the data handling started about seven months ago, the first partial conclusions could be already extracted.

The use of deciduous vegetation permits to take advantage of benefits from vegetation in summer and benefits from the building envelope without vegetation in winter.

The use of other vegetal species with bigger leaves and with a low capacity to retain water would permit to analyze whether the warming effect of solar radiation could be lower regarding the current data registered.

Other measuring procedures with modifications in the vegetal species have being carried out in all the boxes of the experimental research, with the exception of its implementation in one of them. This procedure will permit the development of a comparative study about the responses of the different vegetal species in the same meteorological conditions.

In order to compare the behaviour of façades when a modification in the colour of its components is incorporated, new measures will include some modifications in the colour of the façade without vegetation, as the experimental protocol follows:

Table 1: Experimental protocol.

\begin{tabular}{|c|c|l|}
\hline $\begin{array}{c}\text { FAÇADE WITH } \\
\text { VEGETATION }\end{array}$ & \multicolumn{1}{c|}{$\begin{array}{c}\text { FAÇADE WITHOUT } \\
\text { VEGETATION }\end{array}$} \\
\hline $\begin{array}{c}\text { JUNE 2009 } \\
\text { JULY - DECEMBER } \\
2009\end{array}$ & Metal box with vegetal layer & $\begin{array}{l}\text { Metal box without vegetation that } \\
\text { includes a white paint colour layer } \\
\text { applied in the external surface. }\end{array}$ \\
\hline $\begin{array}{c}\text { JANUARY - JUNE } \\
2010\end{array}$ & Metal box with vegetal layer & $\begin{array}{l}\text { Metal box without vegetation, that } \\
\text { includes a black paint colour layer } \\
\text { applied in the external surface. }\end{array}$ \\
\hline $\begin{array}{c}\text { JULY - DECEMBER } \\
2010\end{array}$ & Metal box with vegetal layer & $\begin{array}{l}\text { Extraction of the metal box, } \\
\text { incorporation of the insulation } \\
\text { material in the external surface. }\end{array}$ \\
\hline
\end{tabular}

\section{Acknowledgements}

The authors acknowledge the financial support provided by Intemper Española S.A. The authors would like to thank also Prof. Dr. Juan Monjo, Mrs. Raquel Guerra and Mrs. Regina Pastor for their significant contributions. 


\section{References}

[1] Kumar, R., Kaushik, SC., Performance Evaluation of Green Roof and Shading for Thermal Protection of Buildings. Building and Environment, vol. 40, pp. 1505-1511, 2005.

[2] Akbari, H., Shade Trees Reduce Building Energy use and CO2 Emissions from Power Plants, Environmental Pollution, vol. 116, pp. 119-126, 2002

[3] Sailor, D.J., A green roof model for building energy simulation programs. Energy and buildings, vol. 40, pp. 1466-1478, 2008

[4] Asaeda, T., Thanh Ca, V., Characteristics of permeable pavement during hot summer weather and impact on the thermal environment. Building and Environment, vol. 35, pp. 363-375, 2000.

[5] Onmura, S., Matsumoto M., Hokoi, S., Study on evaporative cooling effect of roof lawn gardens, Energy and buildings, vol. 33, pp. 653-666, 2001

[6] Neila F.J., Bedoya, C., Acha, C., Olivieri, F., Barbero, M., Las cubiertas ecolólogicas de tercera generación: un nuevo material constructivo, Informes de la construcción, vol.6, pp.15-24, 2008 